Today: Proceedings

Elsevier Editorial System(tm) for Materials

Manuscript Draft

Manuscript Number: MATPR-D-19-03380

Title: Graphene-based microporous layers for enhanced performance in PEM fuel cells

Article Type: ANM2019

Keywords: Polymer Electrolyte Membrane Fuel Cell; Microporous Layer; Graphene; Carbon Black; Water Management; Durability.

Corresponding Author: Dr. Saverio Latorrata, Ph.D.

Corresponding Author's Institution: Politecnico di Milano

First Author: Saverio Latorrata, Ph.D.

Order of Authors: Saverio Latorrata, Ph.D.; Marco Mariani; Paola Gallo Stampino; Cinzia Cristiani; Giovanni Dotelli

Abstract: In this work, the employability of graphene nanoplatelets in the Microporous Layer (MPL) of Polymer Electrolyte Membrane Fuel Cells (PEMFCS) instead of conventional carbon black is studied. This effort is aimed at improving two critical issues that this component faces, which are the water management and the durability under harsh cell operating conditions.

Both morphological and electrical properties of the MPLs produced have been assessed. Distinctive features have been identified, particularly in terms of surface aspect via SEM imaging and porosity through mercury intrusion porosimetry. Electrochemical testing has displayed impressive results for graphene nanoplatelets under low humidity conditions $\left(80{ }^{\circ} \mathrm{C}\right.$ and relative humidity equal to 60\%), compatible with those achieved by carbon black at lower temperature $\left(60^{\circ} \mathrm{C}\right)$, suggesting an improved water retention in the electrolyte that maintains unaltered its ionic conductivity. In addition, a greater reliability and endurance for graphene-based samples have been detected through repetitive testing and cell flooding: little or no voltage losses have been recorded after 13 single cell testing procedures and reduced material detachment has been observed after the cell disassembly, suggesting a superior mechanical resistance by these material. 


\title{
Graphene-based microporous layers for enhanced performance in PEM fuel cells
}

\author{
Saverio Latorrata ${ }^{a^{*}}$, Marco Mariani ${ }^{a}$, Paola Gallo Stampino ${ }^{a}$, Cinzia Cristiani $^{\mathrm{a}}$ and \\ Giovanni Dotelli ${ }^{\mathrm{a}}$
}

${ }^{a}$ Department of Chemistry, Materials and Chemical Engineering "Giulio Natta", Politecnico di Milano, Italy

\begin{abstract}
In this work, the employability of graphene nanoplatelets in the Microporous Layer (MPL) of Polymer Electrolyte Membrane Fuel Cells (PEMFCs) instead of conventional carbon black is studied. This effort is aimed at improving two critical issues that this component faces, which are the water management and the durability under harsh cell operating conditions.

Both morphological and electrical properties of the MPLs produced have been assessed. Distinctive features have been identified, particularly in terms of surface aspect via SEM imaging and porosity through mercury intrusion porosimetry. Electrochemical testing has displayed impressive results for graphene nanoplatelets under low humidity conditions $\left(80^{\circ} \mathrm{C}\right.$ and relative humidity equal to $\left.60 \%\right)$, compatible with those achieved by carbon black at lower temperature $\left(60^{\circ} \mathrm{C}\right)$, suggesting an improved water retention in the electrolyte that maintains unaltered its ionic conductivity. In addition, a greater reliability and endurance for graphene-based samples have been detected through repetitive testing and cell flooding: little or no voltage losses have been recorded after 13 single cell testing procedures and reduced material detachment has been observed after the cell disassembly, suggesting a superior mechanical resistance by these material.
\end{abstract}

Keywords: Polymer Electrolyte Membrane Fuel Cell; Microporous Layer; Graphene; Carbon Black; Water Management; Durability

\footnotetext{
* Corresponding author. Tel.: +39 0223993190; fax: +390223993280.

E-mail address: saverio.latorrata@polimi.it
} 


\section{Introduction}

Climate change and global warming are promoting a drastic transition toward low emission energy generators, which could be employed in both the stationary and the portable industry. In this regard, Polymer Electrolyte Membrane Fuel Cells (PEMFCs) are being increasingly recognized as an excellent solution to this issue. In particular, these devices do not employ traditional fossil fuels, but hydrogen that reacts with an oxidant species producing only water and heat.

Proton exchange membrane fuel cells (PEMFCs) are considered one of the most promising alternatives to internal combustion engines for the production of energy with low pollutant emissions and high conversion efficiency. They do not exploit fossil fuels, but hydrogen, which is a "green" energy vector, combined with an oxidant species that can be pure oxygen or simple air [1].

They are constituted by a series of components placed in series (as seen in Figure 1), each of them accounting for different functions and managing the ongoing chemical-physical phenomena occurring in the cell [2]. The core component is the membrane electrode assembly (MEA) that is constituted by the ionomer, acting as the electrolyte and coated by the catalyst layers (CL) on both of its surfaces. At each side, a gas diffusion medium (GDM) with sealing gaskets is placed. Finally, two bipolar plates (BP) enclose the inner layers, provide the necessary gases to the cell through their flow channels and connect the cell to the external electronic load.

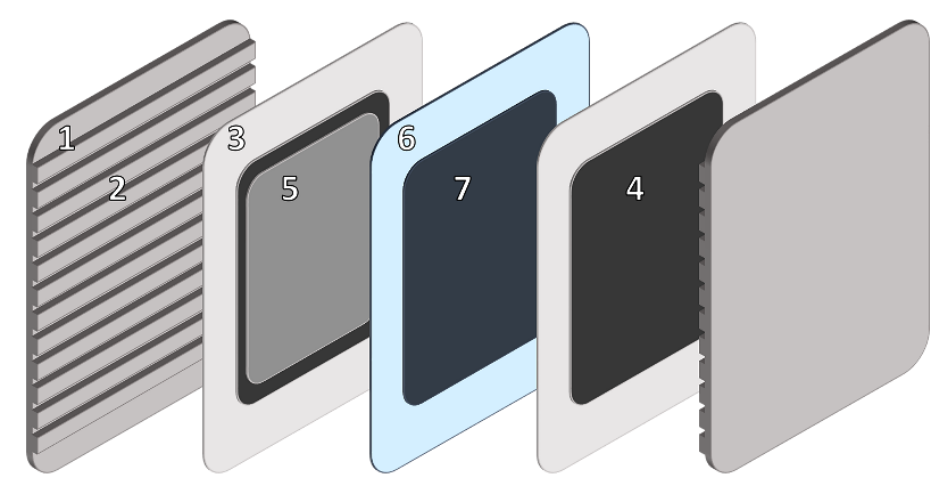

Fig. 1 Simplified structure of a PEMFC: 1) bipolar plate; 2) flow channels; 3) sealing gasket; 4) gas diffusion layer; 5) microporous layer; 6) electrolytic membrane; 7) catalyst layer.

In such devices, water management is a crucial aspect, which must be properly addressed in order to both hydrate the electrolyte, which is necessary for an effective proton conductivity, and avoid the flooding of porous components. In this respect, the GDM is a fundamental component for these purposes [3-4]. Indeed, an excessive accumulation of water could rise diffusive limitations and lead to flooding, above all at high current densities values, where reaction rate is higher. Therefore, GDM needs to be made at the same time hydrophobic and conductive: it is formed by a carbon cloth or paper macro-porous substrate (gas diffusion layer, GDL) and a micro-porous layer (MPL), made from a carbon- and a fluorinated polymer-based ink deposited directly onto the GDL. Such a coating improves the contact with the catalytic layer and allows a faster removal of the produced water [5]. Usually, carbon black (CB) is the conductive phase used in inks for MPLs. In this work, different carbonaceous conductive phases, namely graphene nanoplatelets (GNPs) and carbon black were tested in order to compare the electrochemical performance, the morphology and the durability of the resulting MPLs [6-10].

The use of graphene is promoted by its outstanding properties, such as the exceptional mobility of charge carriers $\left(200,000 \mathrm{~cm}^{2} \mathrm{~V}^{-1} \mathrm{~s}^{-1}\right)$, thermal conductivity $\left(\sim 5000 \mathrm{~W} \mathrm{~m}^{-1} \mathrm{~K}^{-1}\right)$, fracture strength $(\sim 130 \mathrm{GPa})$ and Young's modulus $(\sim 1100 \mathrm{GPa})$ [11-14]. Even though these features are strictly related to specific conditions and to the single-layer 
configuration of graphene, the properties of multi-layer nanoplatelets are still very good and could provide superior performances compared to carbon black.

\section{Experimental}

\subsection{GDM preparation}

The gas diffusion layer employed is a carbon cloth hydrophobized through a specific procedure. After a cleaning treatment in acetone by ultrasonic bath, the material was soaked for 10 minutes per side in a suspension containing 12 wt.\% fluorinated ethylene propylene (FEP). This type of polymer has already proven to reduce the mass transfer resistance in the cell, in particular at high current density, compared to more conventional materials as PTFE [1516]. In addition, its melting point is lower, thus reducing both the sintering temperature and the risks of thermal degradation of the GDL. Indeed, the heat treatment performed on the soaked carbon cloth has a peak temperature of $270{ }^{\circ} \mathrm{C}$, instead of the usual $350{ }^{\circ} \mathrm{C}$ or more needed for PTFE.

The MPL was obtained by coating the GDL with a carbon-based ink. This featured: a main carbon phase, either Vulcan XC72R carbon black or graphene nanoplatelets (Sigma-Aldrich), multi-wall carbon nanotubes, that have proved to increase the conductivity of the GDL, deionized water as solvent, isopropyl alcohol as dispersing agent, FEP as hydrophobizing agent [17-20]. After mechanical stirring at $8000 \mathrm{rpm}$ for 10 minutes, the ink was deposited via doctor blade-coating and heat treated to allow the evaporation of isopropyl alcohol and water. The thickness of the microporous layer coating was set to $40 \mu \mathrm{m}$.

The whole process is schematized in Figure 2.

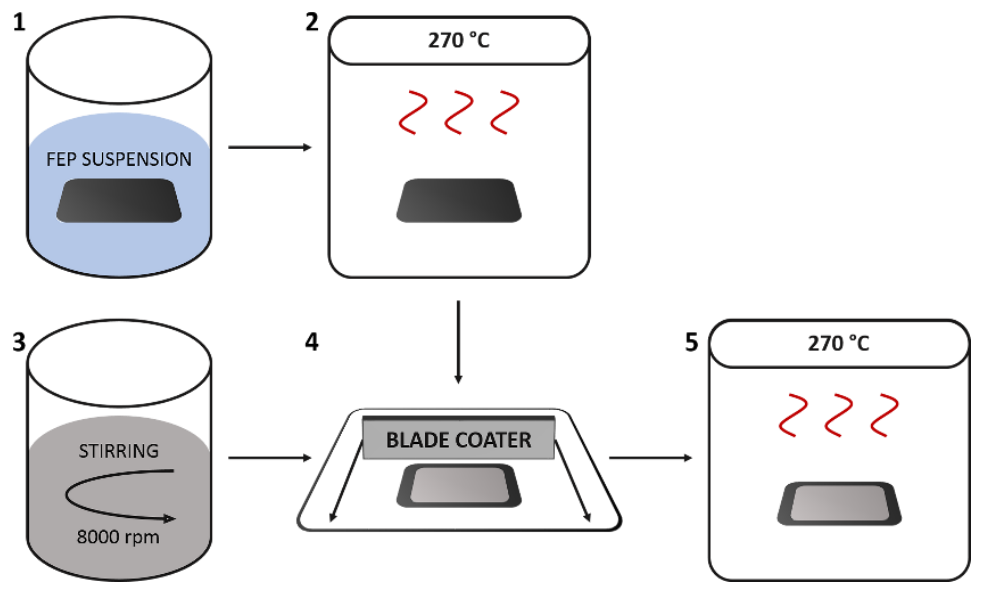

Fig. 2 Scheme of the process of production of the samples: 1) hydrophobization of the carbon cloth GDL; 2) heat treatment on the GDL; 3) preparation of the carbonaceous ink; 4) deposition of the ink on the GDL via blade coating technique; 5) heat treatment on the MPL.

\subsection{Samples characterization}

The samples prepared were morphologically analyzed by scanning electron microscopy (SEM), both before and after fuel cell testing in order to detect damages and deterioration induced by their employment in a functioning cell. These analyses also allowed to perform a qualitative evaluation of the carbon phase distribution, of the MPL porosity and of the presence of cracks and defects.

The wettability of the MPLs surfaces was determined by static contact angle measurements performed on ten different spots of the coating. Again, both the pristine and the already employed samples were analyzed to assess possible variations of their hydrophobicity. 
The samples porosity was assessed by means of mercury intrusion porosimetry (Autopore V 9600). Both the cumulative pore volume and the pore size distribution were evaluated for the samples before and after electrochemical testing in the cell. The dimension of the pore was calculated from the pressure applied to the nonwetting liquid, i.e. mercury, thanks to the Washburn equation (Eq. (1)):

$$
\mathrm{d}=-(4 \gamma \cos \theta) / \mathrm{P}
$$

where $\mathrm{d}$ is the pore diameter, $\theta$ is the contact angle between the pore wall and mercury, $\gamma$ is the mercury surface tension and $\mathrm{P}$ is the external pressure applied to the liquid.

\subsection{Single fuel cell performance testing}

Electrochemical tests were performed in a single cell with a catalyst coated membrane consisting of Nafion 212 and $\mathrm{Pt} / \mathrm{C}$ electrodes, with a platinum loading of $0.2 \mathrm{mg} \mathrm{cm}^{-2}$ at the anode and $0.4 \mathrm{mg} \mathrm{cm}^{-2}$ at the cathode. The stoichiometric ratios were 1.2 and 2 (calculated at $30 \mathrm{~A}$ ) for hydrogen and air respectively.

A first testing session was carried out at either $60^{\circ} \mathrm{C}$ and $80^{\circ} \mathrm{C}$ and relative humidity of the inlet gases of $60 \%$. Then, the values of temperature which produced the best results for the two samples were selected for subsequent experiments:

- $60{ }^{\circ} \mathrm{C}$ for CB-based samples;

- $80{ }^{\circ} \mathrm{C}$ for GNP-based samples.

The polarization curves were recorded from the open-circuit configuration with the current increasing at steps of 2.2 A up to flooding conditions. The current was kept constant for 5 minutes to let the stabilization of the potential value occur. The measurements were repeated 13 times in order to evaluate the reliability of the cell performance and the possible deterioration induced by the repetitive flooding.

\section{Results and discussion}

The SEM images (Figure 3) show that the pristine samples prepared have drastically different features and surface aspect. The CB MPL displays a wide and continuous network of cracks across the whole surface (Figure 3A and $3 \mathrm{~B}$ ). Their length can be up to $1 \mathrm{~mm}$ and their width goes from about $10 \mu \mathrm{m}$ to $50 \mu \mathrm{m}$. The cracking of the surface impedes the integrity of the MPL, which as a result is separated into fragments with a characteristic size smaller than $1 \mathrm{~mm}$.

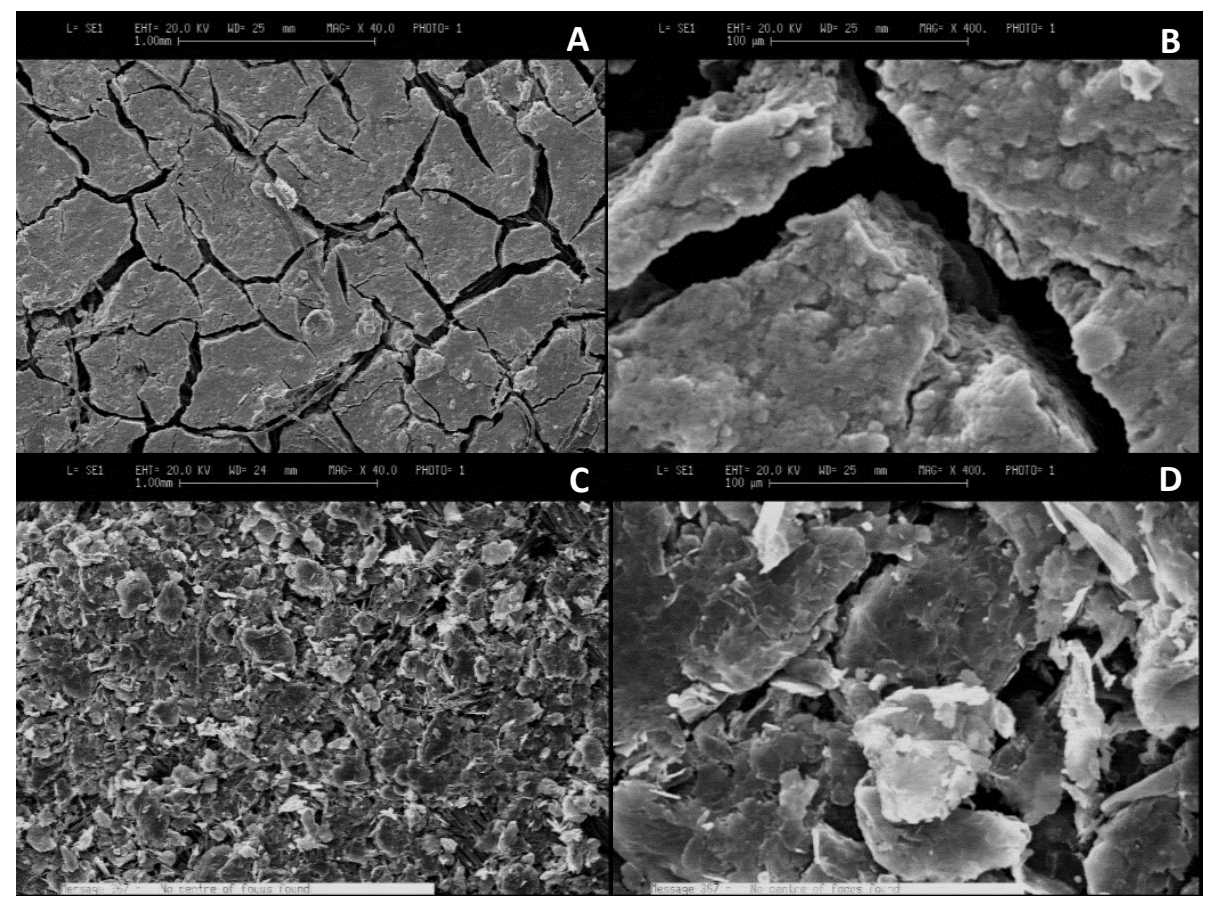

Fig. 3 SEM images before electrochemical testing of: A) CB (40x); B) CB (400x); C) GNP (40x); D) GNP (400x). 


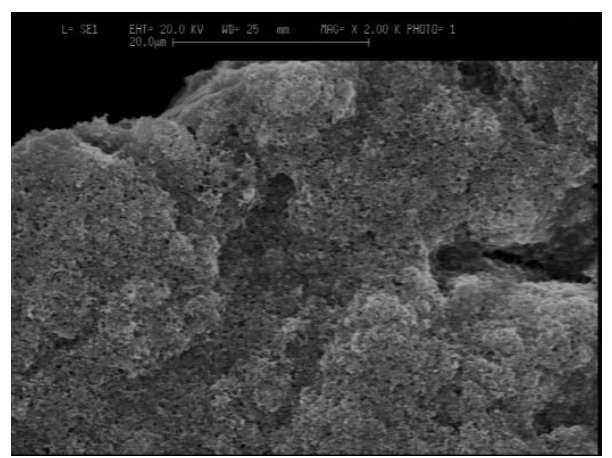

Fig. 4 High magnification (2000x) SEM image of CB MPL with micropores on its surface.

Apart from these macro-defects, the surface of the sample does not show large pores. Indeed, only the micropores inside the CB agglomerates surface can be detected, which are visible in Figure 4 [21-22]. On the contrary, the GNP MPL features a crack-free surface (Figure 3C and 3D). The nanoplatelets are stacked on top of the GDL with their surface generally parallel to the substrate, forming a terrace-like structure with macropores in between the particles $[6,10]$. Despite the presence of voids in between the nanoplatelets, this MPL is not fragmented or otherwise displaying any discontinuity.

In Figure 5, it is possible to notice the effect of compression on both samples during the cell testing [23]. However, it is worth observing that the degree of degradation is different. Indeed, the CB MPL has suffered from the enlargement of the cracks with the probable detachment of some MPL fragments at their edges, as can be seen from Figure 5A and 5B [19]. It is safe to assume that in correspondence of the cracks the gas and water flows are more intense and as a consequence the crack edges are exposed to larger mechanical stresses with respect to the inner areas. On the contrary, Figure 5C and 5D show that the GNP MPL has been flattened but there is no visible detachment of particles or formation of cracks. This is likely due to the continuity of the carbonaceous coating that

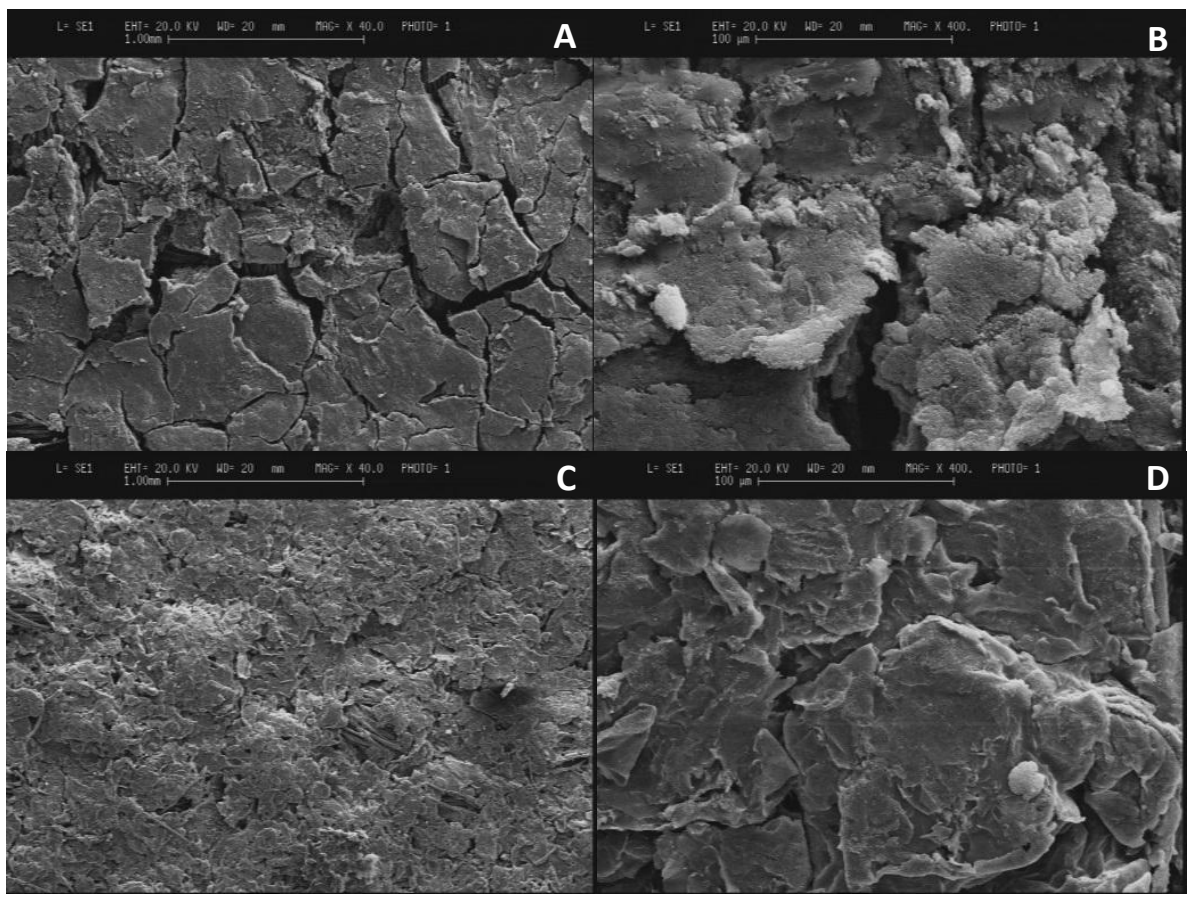

Fig. 5 SEM images after electrochemical testing of: A) CB (40x); B) CB (400x); C) GNP (40x); D) GNP (400x). 
leads to a distribution of the stresses on the whole surface of the MPL, not just on specific spots, thus strongly reducing the risk of material loss during the fuel cell activity.

The wettability of the surfaces prepared has been tested via average static contact angle before and after the single cell testing. As can be seen from the values in Table 1, both samples feature a strong hydrophobic character, with $\mathrm{CB}$ above the super-hydrophobic limit (static contact angle $\geq 150^{\circ}$ ). The main contribution to the hydrophobicity is given by the treatment with FEP and the small difference between the two samples is likely due to the effect of the superficial porosity. Indeed, smaller pores tend to push the liquid phase outward due to capillarity; so CB micropores should repel the water droplet more strongly thus producing larger contact angles, while the GNP macropores tend to produce slightly flatter droplet profiles.

After the testing inside the cell, both samples display a slight increase of the contact angle value. In the case of $\mathrm{CB}$, this could be ascribed to the introduction of defects, which act similarly to the pores in terms of capillary pressure generated below the water droplet. Instead, for GNP the effect of porosity is probably weaker, since the MPL seems to be flattened due to compression in the cell and the gaps between the nanoplatelets are reduced. Therefore, the suction effect of the large pores is present only on specific spots, leading to a larger error in the measurement.

Overall, it can be observed that the variation of the MPLs surface wettability is not significant and does not affect the cell performance. This is likely due to the presence of FEP, which is unaltered after the electrochemical testing.

Table 1 Average static contact angle values for CB and GNP-based MPLs before and after fuel cell testing.

\begin{tabular}{lccc}
\hline \multicolumn{4}{c}{ Static Contact Angle $/{ }^{\circ}$} \\
\hline \multirow{3}{*}{ Before testing } & $\mathrm{CB}$ & GNP & \\
After testing & $151.9 \pm 0.7$ & $144.9 \pm 0.3$ & \\
& $153.0 \pm 0.4$ & $149.6 \pm 2.1$ & (Anodic side) \\
& $154.7 \pm 0.5$ & $145.1 \pm 1.6$ & (Cathodic side) \\
\hline
\end{tabular}

The MPLs produced can be easily distinguished also from their porosities. In Figures 3 and 4, the SEM images show that CB has macro-cracks with a width of several microns and micropores with diameters below $1 \mu \mathrm{m}$ [24]; instead, GNP has macro-pores and holes all in the order of tens of microns. The porosimetry measurements performed before cell testing confirm these first observations. From Figure 6, it can be noticed that the GNP has a larger cumulative pore volume due to the strong presence of macro-pores with a diameter higher than $10 \mu \mathrm{m}$ in the whole coating. $\mathrm{CB}$ has a peak in the macroporous region which is due to the presence of large cracks and a characteristic peak in the microporous region $[8,22]$. This is generated by the porosity inside the CB agglomerates, which has already been described.

Porosimetry analyses in Figure 7 show that both samples have suffered a strong reduction of the cumulative volume of the pores due to the compression during the cell assembling and loss of MPL material during the disassembling [23].
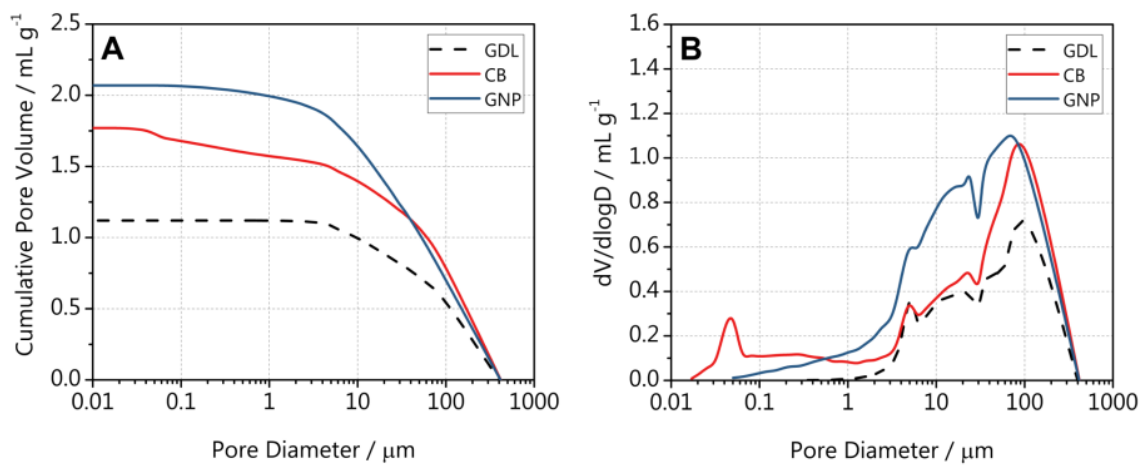

Fig. 6 Porosimetry analysis before fuel cell testing: A) cumulative pore volume curves; B) pore size distribution curves. 
However, the distribution of the pores size has not changed significantly. In particular, it can be noticed that the CB maintains its bimodal pores distribution with peaks both in the macroscopic and microscopic regions. The GNPbased sample seems to feature a peak shift toward larger pore diameters. This could be due to the fact that the compressive stresses close the smaller pores more quickly, thus leaving only the larger ones open.
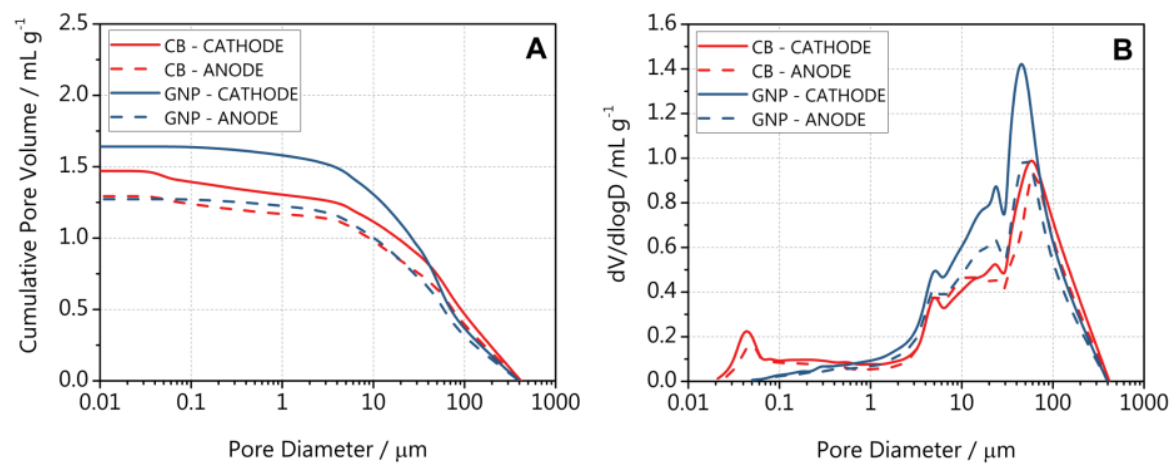

Fig. 7 Porosimetry analysis after fuel cell testing: A) cumulative pore volume curves; B) pore size distribution curves.

\subsection{Single fuel cell testing results}

The preliminary fuel cell testing results shown in Figure 8 reveal that the MPLs employed have a huge impact on the cell behaviour at different temperatures. Indeed, CB (Figure 8A) has a lower ohmic resistance at $80^{\circ} \mathrm{C}$, however the cell experiences a quick flooding since voltage suddenly dropped at around $0.9 \mathrm{~A} \mathrm{~cm}^{-2}$. This is likely due to the additional water that is expelled from the MEA, due to the fast dehydration of the ionomer, which accesses easily into the GDL through the cracks and promotes its occlusion. On the contrary, the GNP (Figure 8B) features a similar voltage at medium current density for both temperatures. At high current density, the best working temperature appears to be $80^{\circ} \mathrm{C}$. In this case, the MPL does not feature large direct paths from the MEA to the GDL (as the macrocracks of $\mathrm{CB}$ ); therefore, it has a stronger "sealing" effect that keeps the water close to the electrolyte. Consequently, the ionomer hydration is preserved and the occlusion of the GDL is delayed.
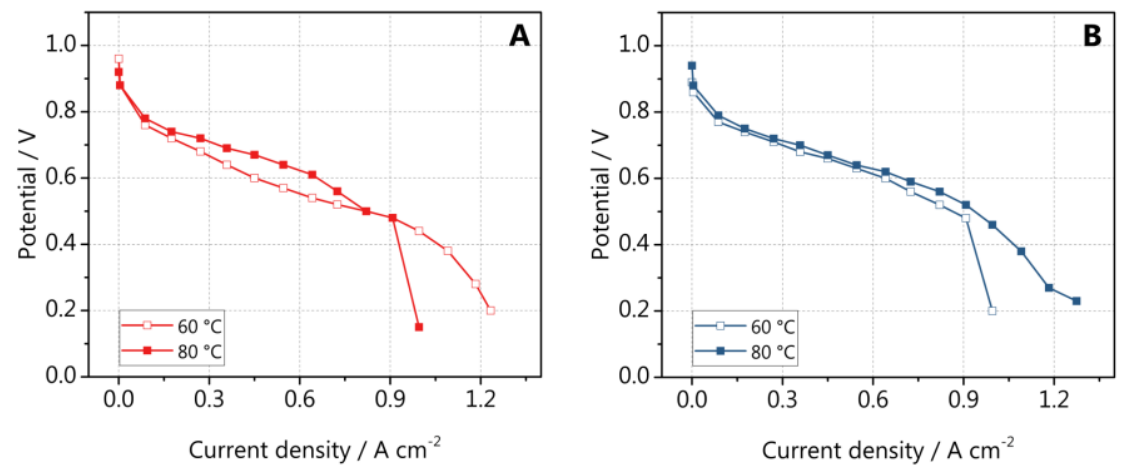

Fig. 8 Polarization curves at $60-80{ }^{\circ} \mathrm{C}$ and $\mathrm{RH}=60 \%$ of fuel cells assembled with A) CB-MPLs and B) GNP-MPLs. 
The graphs in Figure 9 and 10 show that both samples provide decent performances without sharp voltage losses for the entirety of the analyses. In particular, it is worth noticing that CB MPL allows achieving higher power densities, with the maximum value equal to $0.472 \mathrm{~W} \mathrm{~cm}^{-2}$ at $0.91 \mathrm{~A} \mathrm{~cm}^{-2}$ during session 4 (Figure 8B), and delayed flooding for most of the curves (Figure 9A). This confirms that carbon black is an optimal material for MPLs, in particular because of its bimodal porosity that promotes a proper water management at low temperatures.

However, it is evident from Figures $10 \mathrm{~A}$ and $10 \mathrm{~B}$ that, despite a lower peak power density achieved $\left(0.436 \mathrm{~W} \mathrm{~cm}^{-2}\right.$ at $0.87 \mathrm{~A} \mathrm{~cm}^{-2}$ during sessions $4,5,6$ and 7), GNP is the most reliable material out of the two. Indeed the worst session (black line) deviates from the best one (green line) only at high current density, probably due to residual water in the cell that anticipated flooding during the first three sessions. If these measurements are excluded, the peak power density has a maximum variation of $0.009 \mathrm{~W} \mathrm{~cm}^{-2}$ between the best and the worst performances. Instead, that of $\mathrm{CB}$ is equal to $0.055 \mathrm{~W} \mathrm{~cm}^{-2}$.
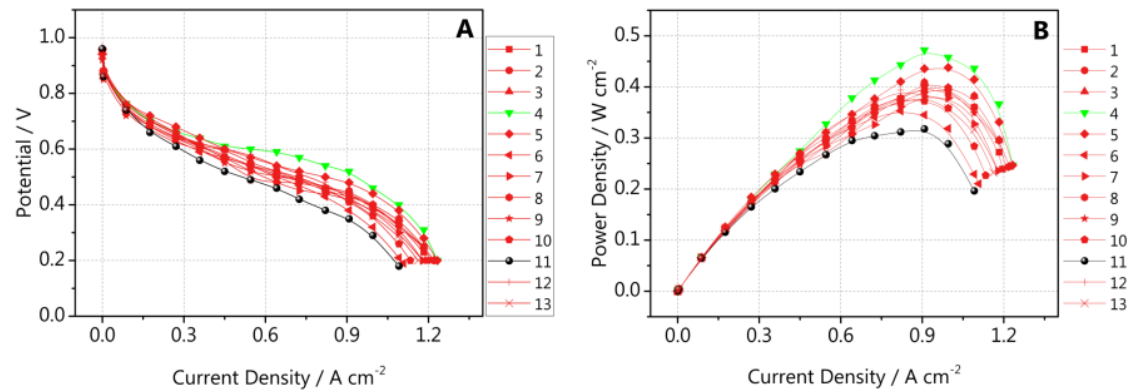

Fig. 9 A) Polarization curves and B) Power density curves of fuel cells assembled with CB-MPL at $60{ }^{\circ} \mathrm{C}$ and $\mathrm{RH}=60 \%$.
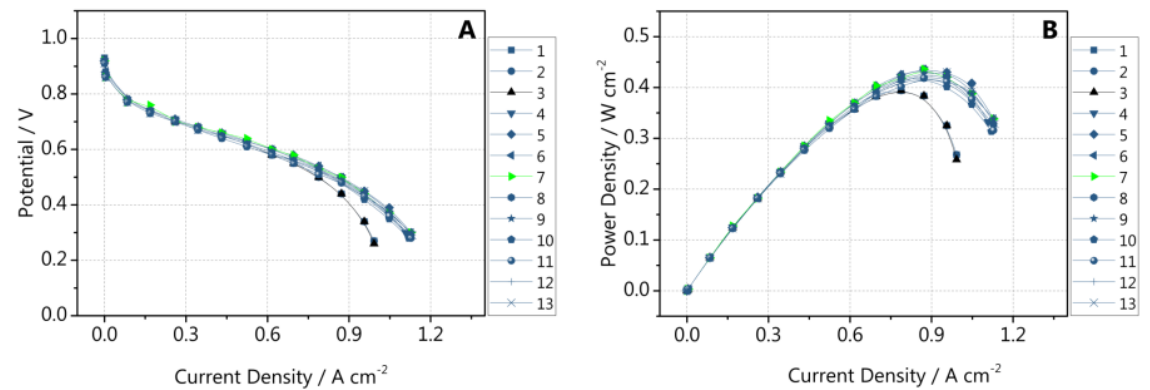

Fig. 10 A) Polarization curves and B) Power density curves of fuel cells assembled with GNP-MPL at $80{ }^{\circ} \mathrm{C}$ and $\mathrm{RH}=60 \%$.

The graphs in Figure 11 remark once again that $\mathrm{CB}$ provides the best single performance with the peak power density equal to $0.472 \mathrm{~W} \mathrm{~cm}^{-2}$, the ohmic resistance of $0.218 \Omega \mathrm{cm}^{2}$ and the mass transfer resistance of $0.060 \Omega \mathrm{cm}^{2}$. However, GNP provides optimal performances during the whole testing with average values of $0.420 \mathrm{~W} \mathrm{~cm}^{-2}$ for the maximum power density and $0.328 \Omega \mathrm{cm}^{2}$ and $0.098 \Omega \mathrm{cm}^{2}$ for the ohmic and mass transfer resistances respectively. These results are significant because they have been achieved in a dry cell environment $\left(80{ }^{\circ} \mathrm{C}\right.$ and $\left.\mathrm{RH}=60 \%\right)$ that usually compromises the performance of the fuel cells with CB-based MPLs due to excessive dehydration of the electrolyte. This is of great importance because reduces the dependence of the PEM fuel cells on external water humidifiers, which complicate the system structure and increase its dimension. 

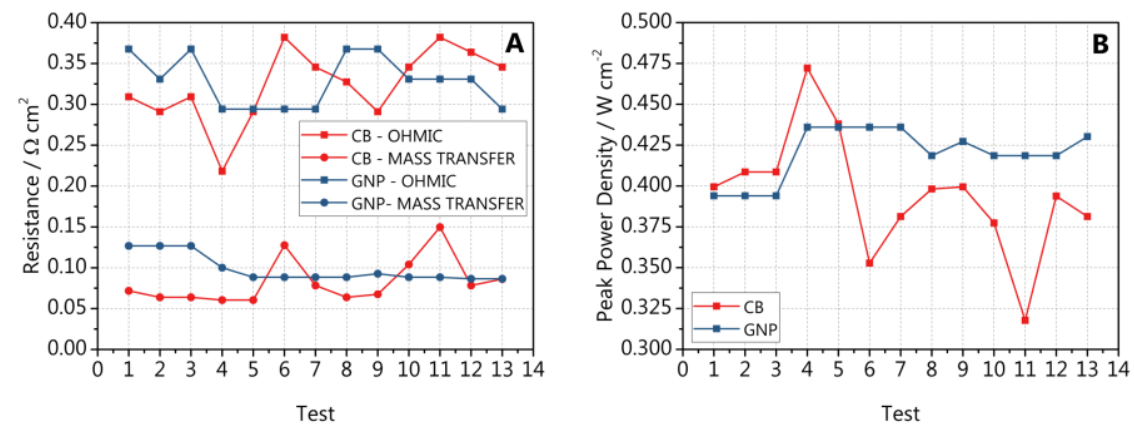

Fig. 11 Values recorded for CB and GNP of: A) Ohmic and Mass Transfer Resistances; B) Peak Power Density

\section{Conclusions}

The substitution of conventional carbon black with graphene nanoplatelets has revealed that large improvements can be achieved in the production of microporous layers for PEMFCs. The employment of these alternative particles has allowed to provide a viable solution to some issues that have constantly affected PEM fuel cells, which are the water management under low humidity conditions and the durability of the components after critical events, such as cell flooding at high current density.

Indeed, the MPL with graphene has provided great electrical performances at $80{ }^{\circ} \mathrm{C}$ at par with those achieved by carbon black at $60{ }^{\circ} \mathrm{C}$. The innovative material has allowed the conservation of the hydration level of the electrolyte, which is critical to the functioning of the cell at high temperatures and is directly related to the ionic conductivity of this component; therefore, an excellent water management has been granted.

Finally, the graphene-based MPL has displayed a superior mechanical strength that has granted an almost perfect preservation of the component integrity through the cell testing and disassembling, differently from the carbon black-based material that has suffered from extensive degradation likely due to the presence of large macro-cracks in the sample.

\section{References}

[1] L. Barreto, A. Makihira, K. Riahi, Int J Hydrogen Energ 2003, 28, 267-284.

[2] Y. Wang, K. S. Chen, J. Mishler, S. C. Cho, X. C. Adroher, Appl Energ 2011, 88, 981-1007.

[3] J. Chen, T. Matsuura, M. Hori, J Power Sources 2004, 131, 155-161.

[4] N. Zamel, X. G. Li, Prog Energ Combust 2013, 39, 111-146.

[5] E. Nishiyama, M. Hara, T. Murahashi, K. Nakao, J Fuel Cell Sci Tech 2015, 12, 051005-051005-051007.

[6] M. J. Leeuwner, A. Patra, D. P. Wilkinson, E. L. Gyenge, J Power Sources 2019, 423, 192-202.

[7] A. Ozden, S. Shahgaldi, J. Zhao, X. G. Li, F. Hamdullahpur, Fuel 2018, 215, 726-734.

[8] A. Ozden, S. Shahgaldi, X. G. Li, F. Hamdullahpur, Renew Energ 2018, 126, 485-494.

[9] A. T. Najafabadi, M. J. Leeuwner, D. P. Wilkinson, E. L. Gyenge, ChemSusChem 2016, 9, 1689-1697.

[10] M. J. Leeuwner, D. P. Wilkinson, E. L. Gyenge, Fuel Cells 2015, 15, 790-801.

[11] A. A. Balandin, Carbon Nanotubes, Graphene, and Associated Devices Iv 2011, 8101.

[12] C. Lee, X. D. Wei, J. W. Kysar, J. Hone, Science 2008, 321, 385-388.

[13] X. Du, I. Skachko, E. Y. Andrei, Int J Mod Phys B 2008, 22, 4579-4588.

[14] A. A. Balandin, S. Ghosh, W. Z. Bao, I. Calizo, D. Teweldebrhan, F. Miao, C. N. Lau, Nano Lett 2008, 8, 902-907.

[15] S. Latorrata, R. Balzarotti, P. G. Stampino, C. Cristiani, G. Dotelli, M. Guilizzoni, Prog Org Coat 2015, 78, 517-525.

[16] S. Latorrata, P. G. Stampino, C. Cristiani, G. Dotelli, Int J Hydrogen Energ 2014, 39, 5350-5357.

[17] S. Latorrata, P. G. Stampino, C. Cristiani, G. Dotelli, Int J Hydrogen Energ 2015, 40, 14596-14608. 
[18] S. Y. Lin, M. H. Chang, Int J Hydrogen Energ 2015, 40, 7879-7885.

[19] S. Latorrata, P. G. Stampino, C. Cristiani, G. Dotelli, Energies 2017, 10.

[20] S. Latorrata, P. G. Stampino, C. Cristiani, G. Dotelli, Chem Engineer Trans 2014, 41, 241-246.

[21] E. Passalacqua, G. Squadrito, F. Lufrano, A. Patti, L. Giorgi, J Appl Electrochem 2001, 31, 449-454.

[22] X. L. Wang, H. M. Zhang, J. L. Zhang, H. F. Xu, X. B. Zhu, J. Chen, B. L. Yi, J Power Sources 2006, 162, 474-479.

[23] M. B. Sassin, Y. Garsany, B. D. Gould, K. Swider-Lyons, J Electrochem Soc 2016, 163, F808-F815.

[24] C. Simon, D. Kartouzian, D. Muller, F. Wilhelm, H. A. Gasteiger, J Electrochem Soc 2017, 164, F1697F1711. 


$$
\text { Cadd }
$$



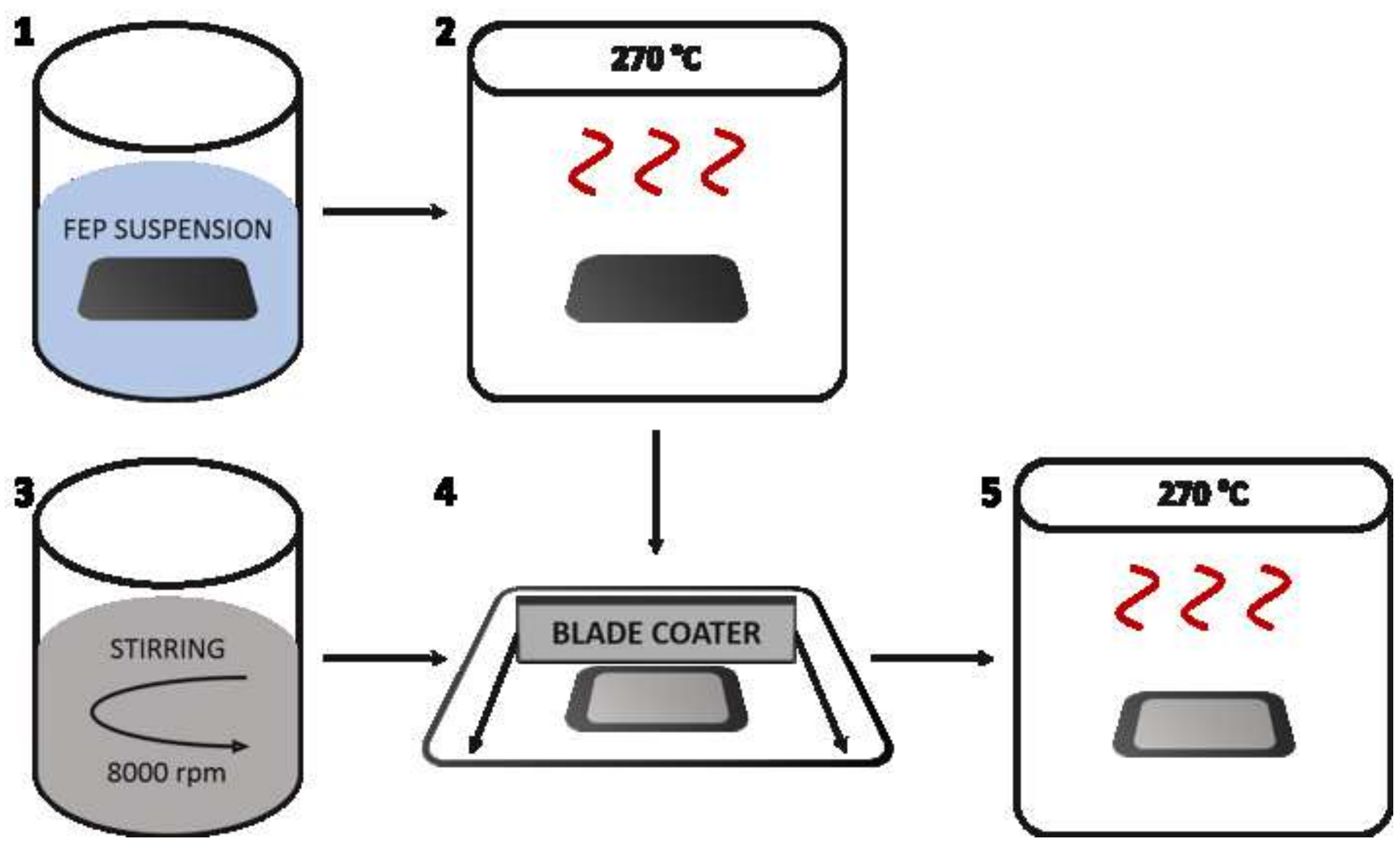
Click here to download high resolution image
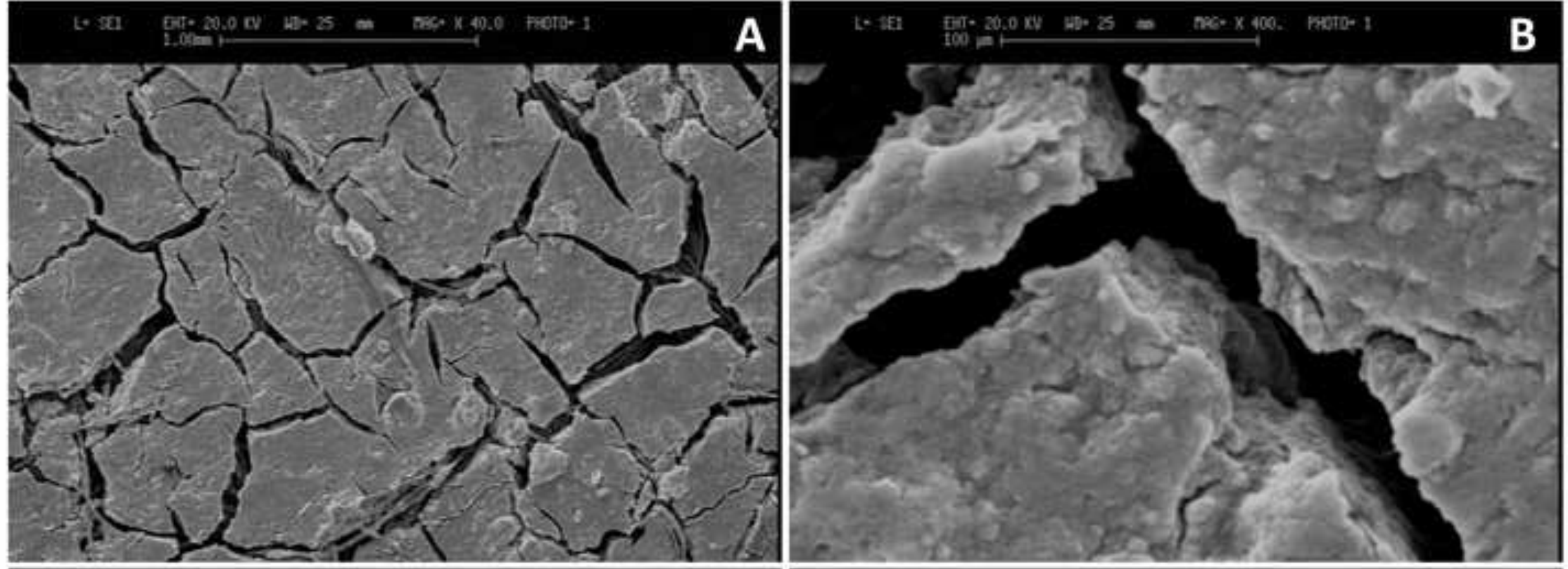

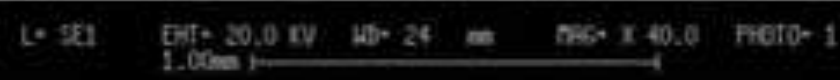

C

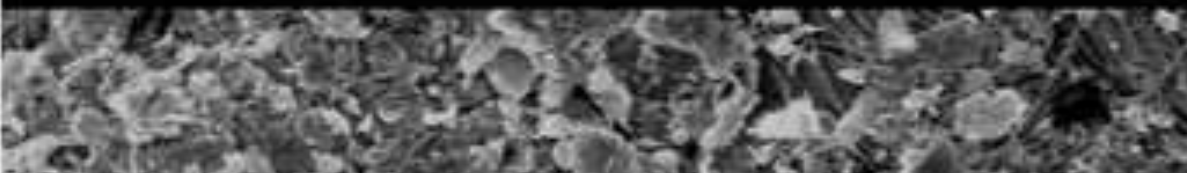

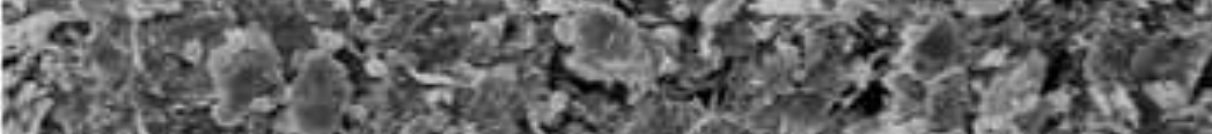
- 3 -

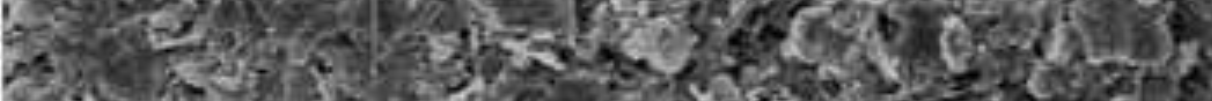
15.

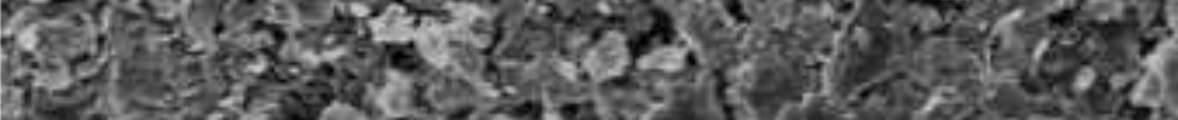

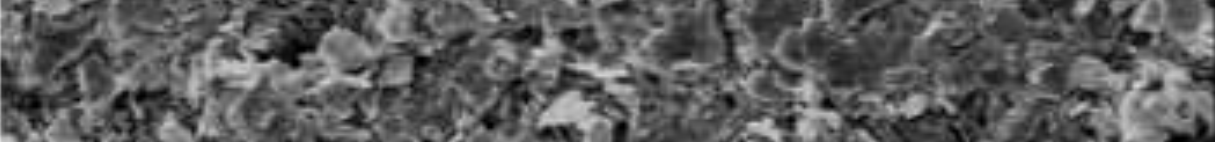

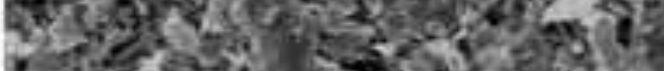

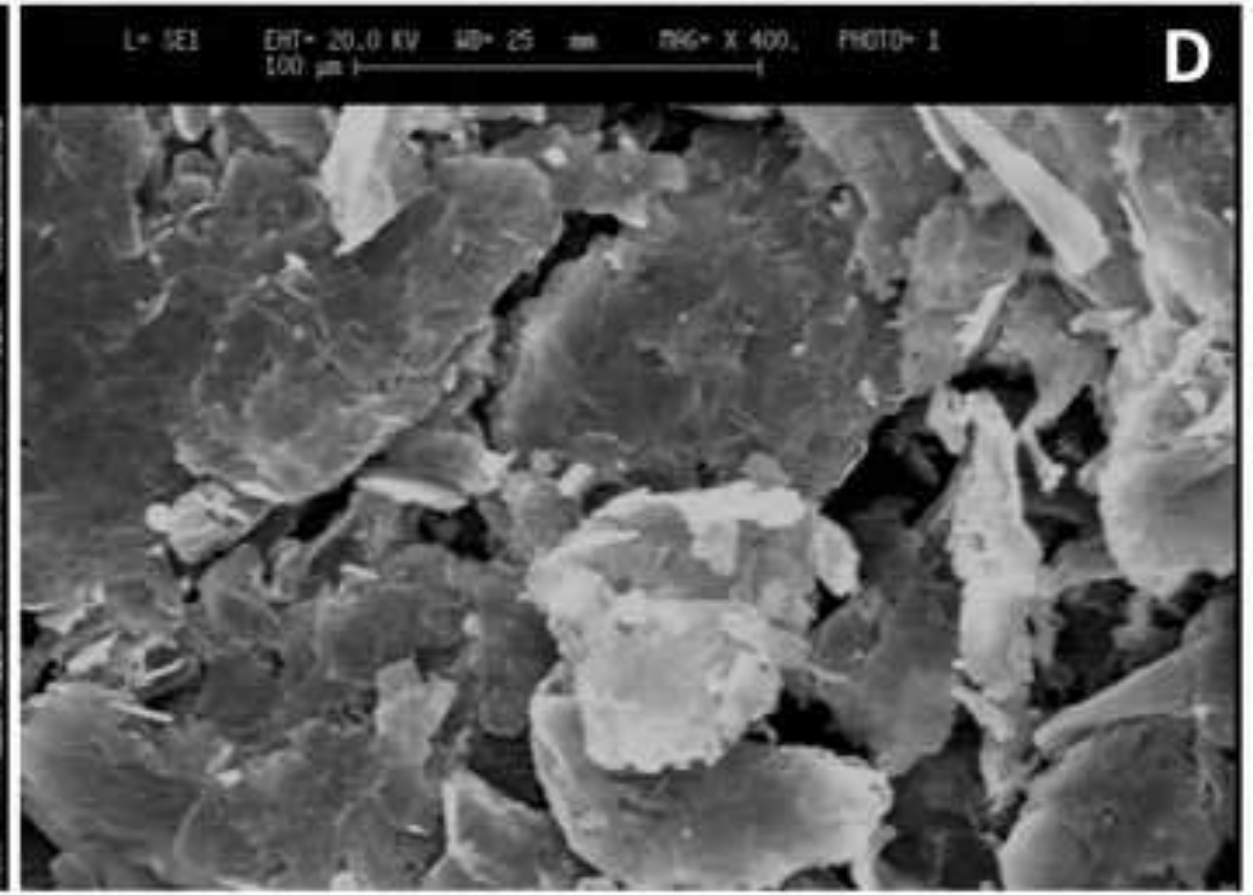



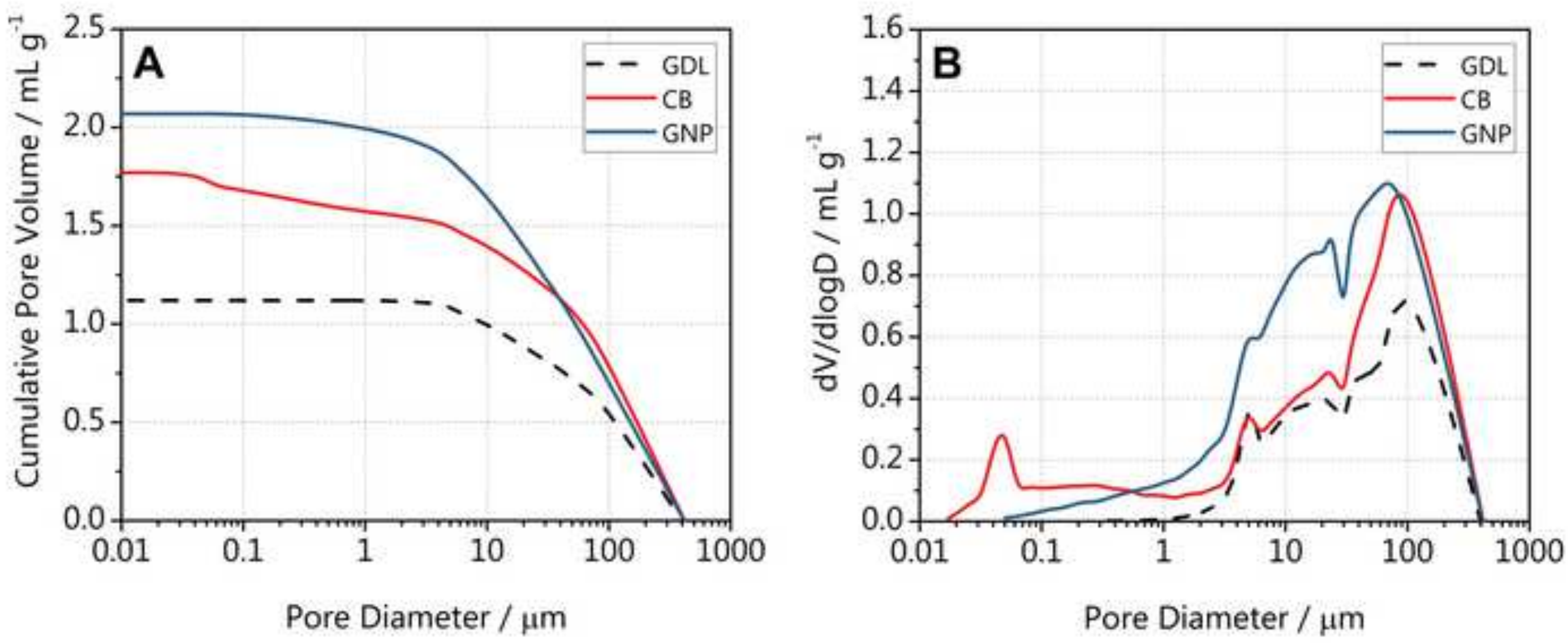

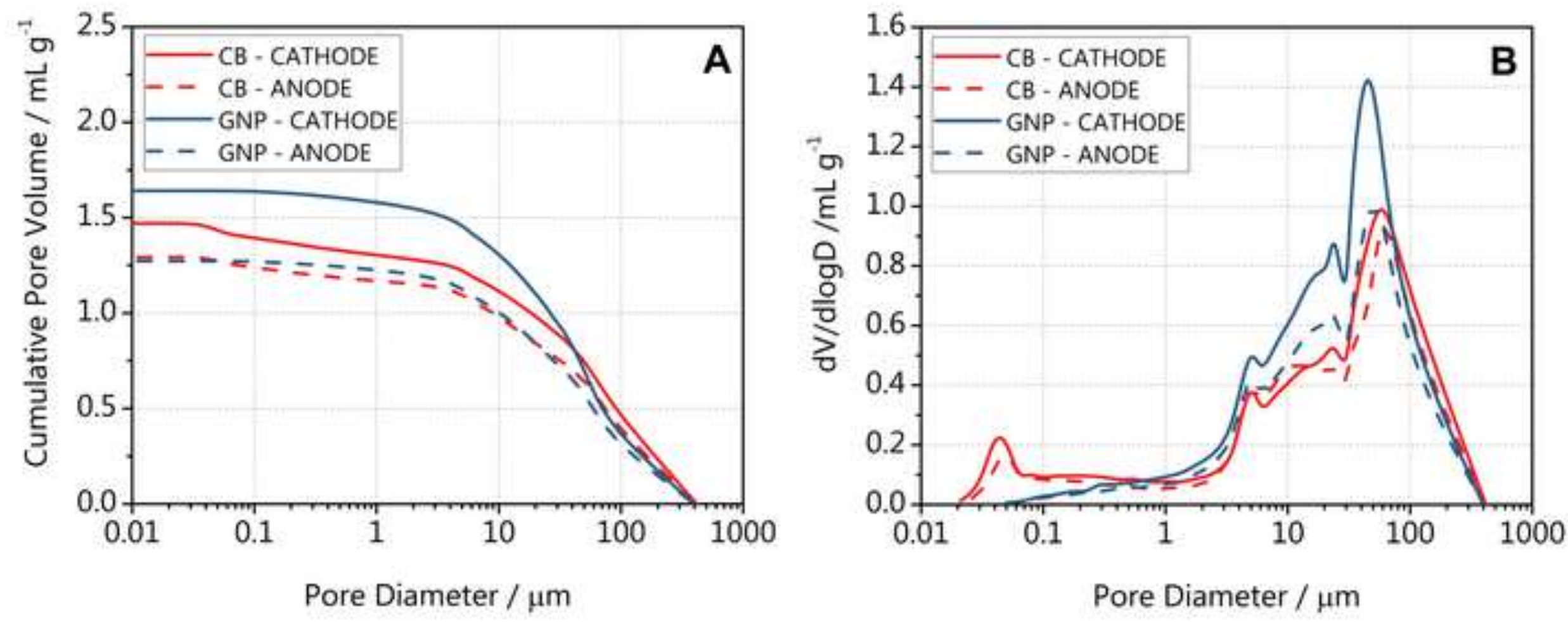

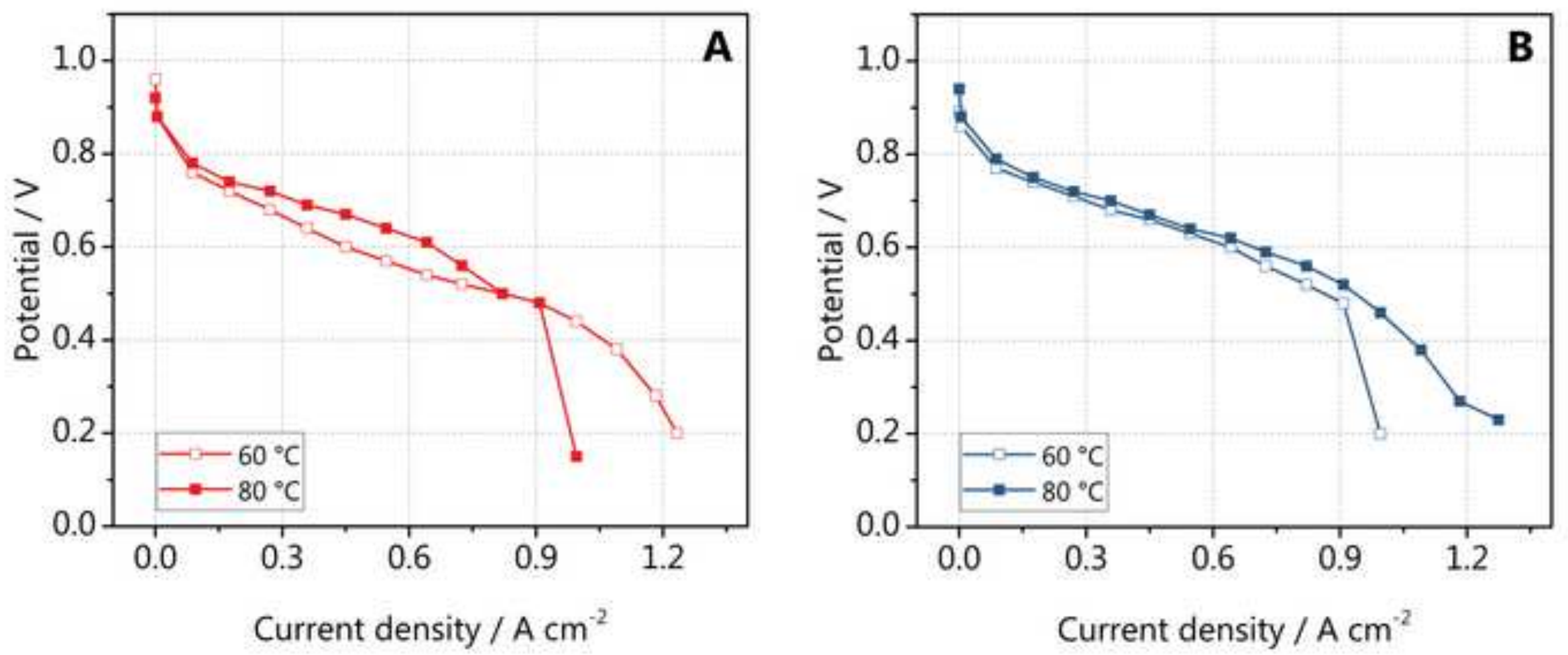

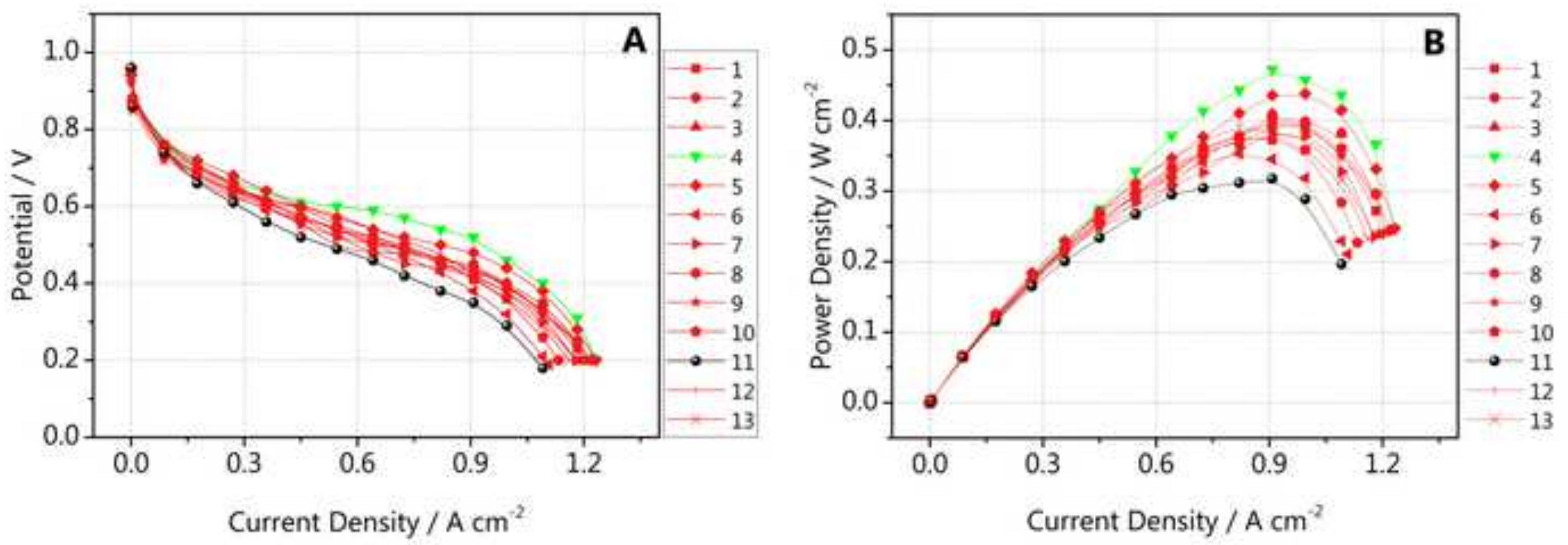

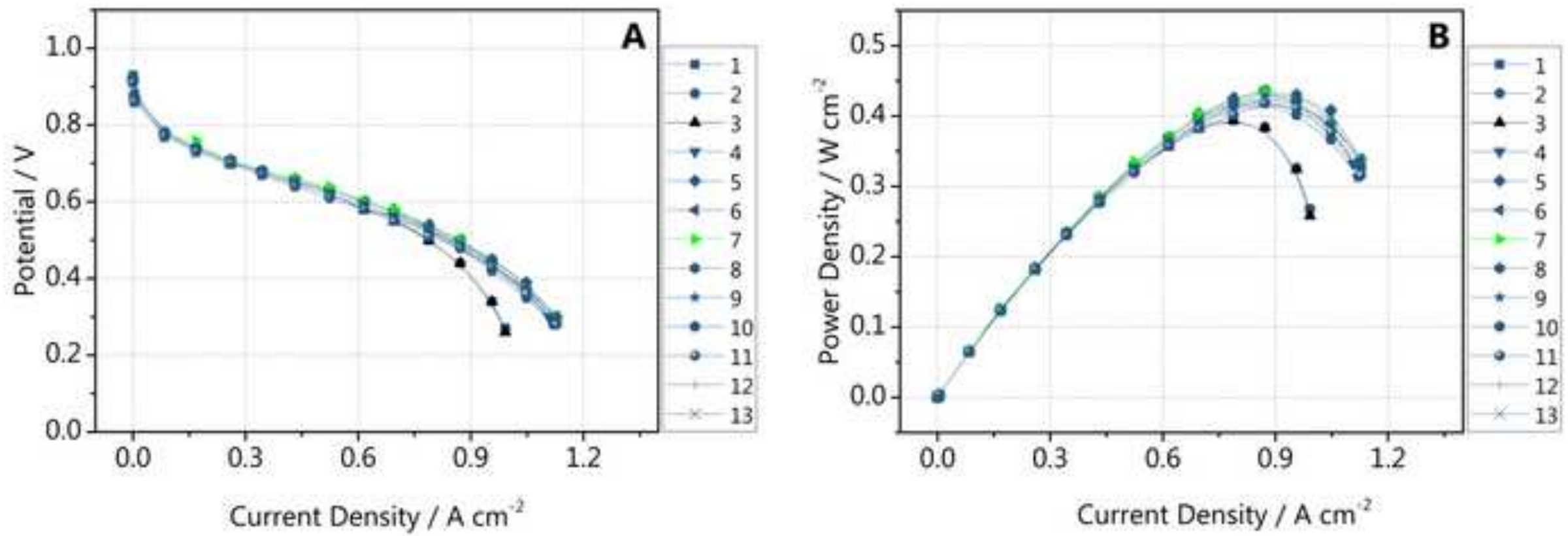

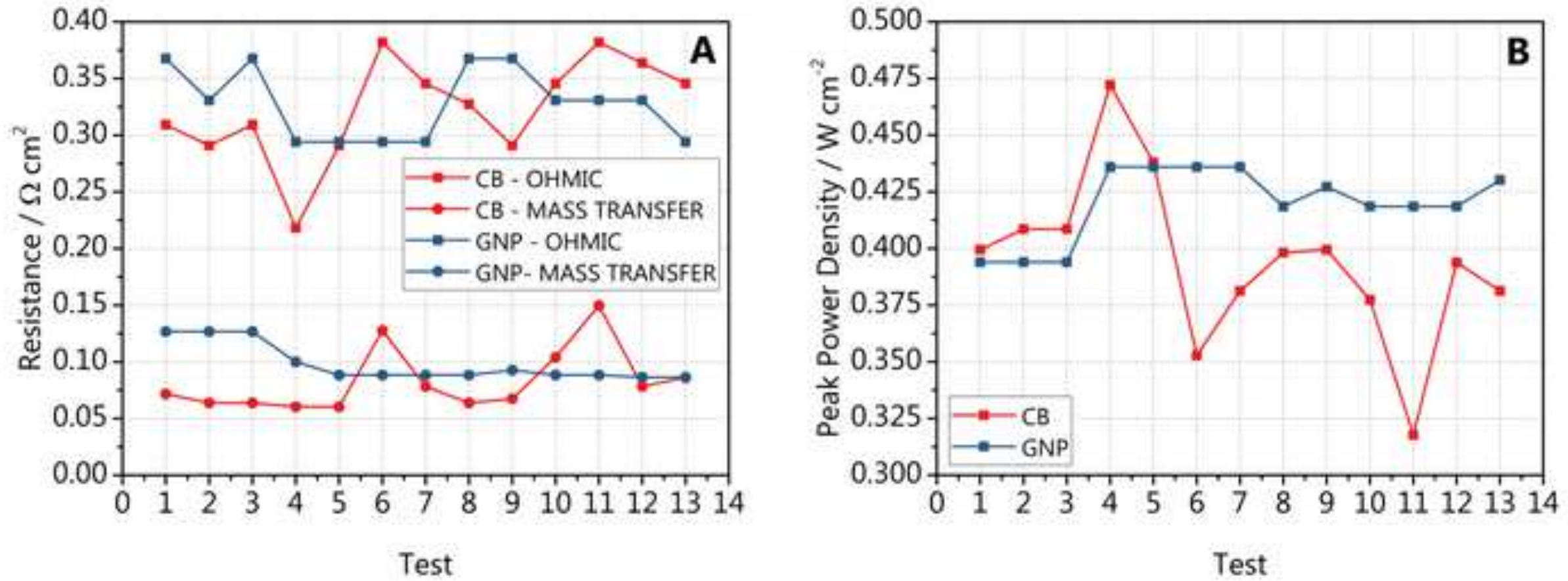